DOI: $10.2478 / \mathrm{v} \cdot 10169-011-0018-0$

\title{
INFLUENCE OF HYBRID FIBERS ON TOUGHNESS BEHAVIOR OF HIGH STRENGTH FLOWING CONCRETE
}

\author{
EETHAR THANON DAWOOD ${ }^{1}$, MAHYUDDIN RAMLI ${ }^{2}$
}

\begin{abstract}
This study investigates the use of steel fibers and hybrid composite with a total fibers content of $2 \%$ on the high strength flowing concrete and determines the density, compressive strength, static modulus of elasticity, flexural strength and toughness indices for the mixes. The results show that the inclusion of more than $0.5 \%$ of palm fibers in hybrid fibers mixes reduces the compressive strength. The hybrid fibers can be considered as a promising concept and the replacement of a portion of steel fibers with palm fibers can significantly reduce the density, enhance the flexural strength and toughness. The results also indicates that the use of hybrid fibers $(1.5$ steel fibers $+0.5 \%$ palm fibers) in specimens increases significantly the toughness indices and thus the use of hybrid fibers combinations in reinforced concrete would enhance their flexural toughness \& rigidity and enhance their overall performances.
\end{abstract}

Key words: Hybrid fibers, high strength flowing concrete.

\section{INTRODUCTION}

It is well known that concrete is a brittle material under tensile loading. The mechanical properties of concrete can be improved by randomly oriented short discrete fibers which prevent or control initiation, propagation, or coalescence of cracks [1].

For concrete consisting of hardened cement paste and aggregates of different sizes, micro cracks or porosity are among the intrinsic factors which can be overcome by using fibers reinforcement. The main disadvantage of incorporating a fibers is the loss of workability and the increased difficulty of casting. This status mostly results in insufficient workability and high volumes of entrapped air in concrete which leads to reduction in its strength and durability [2]. The modern concrete can be designed to have a high workability that allows the concrete to flow in the congested reinforcement areas and fill complicated formwork without segregation [3-5].

\footnotetext{
${ }^{1} \mathrm{PhD}$ - School of Housing, Building \& Planning - Universiti Sains Malaysia 11800 Penang-Malaysia, e-mail: eethar2005@yahoo.com.

${ }^{2}$ Dean-School of Housing, Building \& Planning - University Sains Malaysia/ Penang-Malaysia, e-mail: mahyudin@usm.my
} 
The character and the performance of fibers reinforced concrete (FRC) change, depending on the properties of concrete and the fibers. The properties of fibers that are usually of interest are fibers concentration, fibers geometry, fibers orientation, and fibers distribution. Moreover, the use of a single type of fibers may improve the properties of FRC to a limited level. However the concept of hybridization, which is the process of adding two or more types of fibers into concrete, can offer more attractive engineering properties as the presence of one fibers enables the more efficient utilization of the potential properties of the other fibers [6]. It has been shown from previous studies [7-9] that the concept of hybridization with two different fibers incorporated in a common cement matrix can offer more attractive engineering properties because the presence of one fibers enables the more effective utilization of the potential properties for the other fibers.

Steel fibers has a considerably larger length and higher Young's modulus of elasticity as compared to the other fibers-types. This leads to an improved flexural rigidity and has great potential for crack control, although the volumetric density is high. It is also important to note that steel is conductive in both electric and magnetic fields and hence, the steel fibers content has to be reduced to a certain level. Optimization of mechanical and conductivity properties can be achieved by combining different types and sizes of fibers, such as in the case of palm fibers and steel fibers. According to Bentur \& Mindess [8], the attractive advantage of hybrid fibers system is that it provides a system in which one type of fibers, which is stronger and stiffer, improves the first crack stress and ultimate strength, where the second type of fibers, which is more flexible and ductile, leads to the improved toughness and strain capacity in the post-cracking zone. It also contributes to a hybrid reinforcement, in which the smaller fibers bridges microcracks and enhance, reduce crack widths. This leads to a higher tensile strength of the composite. The second type of fibers is larger, so that it can arrest the propagating macrocracks and can substantially improve the toughness of the composite.

However, most of the research work and utilization of fibers reinforcement are about monotype fibers. Using hybrid fibers as reinforcement to improve the performance of concrete are not frequently reported. Therefore, the research would present the results of some properties of high strength flowing concrete reinforced by different volume fractions of mono-steel fibers and the hybridization of steel fibers with palm fibers.

\section{Materials AND MIX PROPORTIONS}

\subsection{Materials}

The cement used in concrete mixtures was ordinary portland cement type I from Tasek Corporation Berhad. Silica fume was obtained from Scancem Materials Sdn. Bhd. and 
was used as partial replacement of cement. The chemical compositions of ordinary portland cement and silica fume are stated in Table 1.

Table 1

Chemical composition of ordinary portland cement and silica fume:

\begin{tabular}{|l|c|c|}
\hline \multirow{2}{*}{ Constituent } & $\begin{array}{c}\text { Ordinary Portland } \\
\text { Cement Type I }\end{array}$ & Silica fume \\
\cline { 2 - 3 } & $\%$ by weight & $\%$ by weight \\
\hline Lime $(\mathrm{CaO})$ & 64.64 & $1.0 \%(\max )$ \\
\hline Silica $(\mathrm{SiO} 2)$ & 21.28 & $90 \%(\max )$ \\
\hline Alumina(A12O3) & 5.60 & $1.2 \%(\max )$ \\
\hline Iron Oxide( Fe2O3) & 3.36 & $2.0 \%(\max )$ \\
\hline Magnesia(MgO) & 2.06 & $0.6 \%(\max )$ \\
\hline Sulphur Trioxide $(\mathrm{SO} 3)$ & 2.14 & $0.5 \%(\max )$ \\
\hline N2O & 0.05 & $0.8 \%(\max )$ \\
\hline Loss of Ignition & 0.64 & $6 \%(\max )$ \\
\hline Lime saturation factor & 0.92 & - \\
\hline C3S & 52.82 & - \\
\hline C2S & 21.45 & - \\
\hline C3A & 9.16 & - \\
\hline C4AF & 10.2 & - \\
\hline
\end{tabular}

The superplasticizer (SP.) is Conplast SP1000 obtained from Fosroc Sdn. Bhd. and was used to establish the desired workability of mixes. The fine aggregate was natural sand, with fineness modulus of 2.86 and maximum size of less than $5 \mathrm{~mm}$. The palm fibers is supplied by Fibers-X (M) Sdn. Bhd, and their characteristics as are shown in Table 2. The steel fibers is supplied by Hunan Sunshine Steel Fibers Co. Ltd, and their mechanical properties are presented in Table 3.

Characteristics of palm fibers:

Table 2

\begin{tabular}{|l|c|}
\hline \multicolumn{1}{|c|}{ Fibers Properties } & Quantity \\
\hline Average fibers length,(mm) & 30 \\
\hline Average fibers width $(\mathrm{mm})$ & 0.021 \\
\hline Tensile strength(MPa) & 21.2 \\
\hline Elongation at break (\%) & 0.04 \\
\hline Specific gravity & 1.24 \\
\hline Water absorption\%,24/48 hrs & 0.6 \\
\hline
\end{tabular}


Table 3

Characteristics of Steel fibers:

\begin{tabular}{|l|c|}
\hline \multicolumn{1}{|c|}{ Fibers Properties } & Quantity \\
\hline Average fibers length, $(\mathrm{mm})$ & 30 \\
\hline Average fibers width, $(\mathrm{mm})$ & 0.56 \\
\hline (d/L) Aspect ratio & 54 \\
\hline Tensile strength(MPa) & $>1100$ \\
\hline Ultimate elongation $(\%)$ & $<2$ \\
\hline Specific gravity & 7.850 \\
\hline
\end{tabular}

2.2. Mix PROPORTIONS

The design of concrete compositions is given in Table 4. Fourteen concrete mixes were prepared using water-binder (Cement+ Silica fume) ratio of 0.43 and silica fume replacement was $10 \%$. The amount of cement, silica fume, sand and free water were kept constant. The amount of superplasticizer was varied from 1.8 to $2.2 \%$ by weight of binder materials to maintain the workability and the uniformity of the mixes. The mix design of the control mix ( $\mathrm{CF} 0$ ) is carried out according to the absolute volume method given by the American Concrete Institute (ACI) [10] for the flowing high strength concrete. The steel fibers is added to the mixes according to the volumetric fractions of $2.0 \%$ by weight of cement (mix CF1). However, the use of hybrid fibers at $2 \%$ was used but with different amounts for each of palm fibers and steel fibers in mixes (CF2-CF7).

Table 4

Concrete Mixes proportions:

\begin{tabular}{|l|c|c|c|c|c|c|c|c|c|c|}
\hline Index & $\begin{array}{c}\text { Cement } \\
\mathbf{K g} / \mathbf{m}^{3}\end{array}$ & $\begin{array}{c}\text { Silica } \\
\mathbf{f u m e} \\
\mathbf{K g} / \mathbf{m}^{3}\end{array}$ & $\begin{array}{c}\text { Water } \\
\mathbf{K g} / \mathbf{m}^{3}\end{array}$ & $\mathbf{S P \%}$ & $\begin{array}{c}\text { Sand } \\
\mathbf{K g} / \mathbf{m}^{3}\end{array}$ & $\begin{array}{c}\mathbf{G r a v e l} \\
\mathbf{K g} / \mathbf{m}^{3}\end{array}$ & $\mathbf{W + S P / B}$ & $\begin{array}{c}\text { Steel } \\
\text { fibers } \\
\mathbf{( S F})\end{array}$ & $\begin{array}{c}\text { Palm } \\
\text { fibers } \\
(\mathbf{P M F}) \\
\mathbf{\%}\end{array}$ & $\begin{array}{c}\text { Slump } \\
\mathbf{f l o w} \\
(\mathbf{m m})\end{array}$ \\
\hline CF0 & 500 & 50 & 235 & 1.8 & 880 & 715 & 0.43 & 0 & - & 650 \\
\hline CF1 & 500 & 50 & 235 & 2.2 & 880 & 715 & 0.43 & 2.0 & - & 560 \\
\hline CF2 & 500 & 50 & 235 & 2.2 & 880 & 715 & 0.43 & 1.75 & 0.25 & 570 \\
\hline CF3 & 500 & 50 & 235 & 2.2 & 880 & 715 & 0.43 & 1.50 & 0.50 & 580 \\
\hline CF4 & 500 & 50 & 235 & 2.2 & 880 & 715 & 0.43 & 1.25 & 0.75 & 590 \\
\hline CF5 & 500 & 50 & 235 & 2.0 & 880 & 715 & 0.43 & 1.0 & 1.0 & 590 \\
\hline CF6 & 500 & 50 & 235 & 2.0 & 880 & 715 & 0.43 & 0.75 & 1.25 & 600 \\
\hline CF7 & 500 & 50 & 235 & 2.0 & 880 & 715 & 0.43 & 0.50 & 1.50 & 610 \\
\hline
\end{tabular}




\section{TEST METHODS}

Each test result is represented by three cube samples $100 \mathrm{~mm}$ and tested to determine their density and compressive strength at various ages after undergoing water curing. The testing machine with a capacity of $100 \mathrm{Kn}$ was used. The slump test for the mixes was performed according to ASTM C143 with a targeted slump flow of 600 $\mathrm{mm} \pm 50 \mathrm{~mm}$. The cube specimens were left in the moulds for 24 hours after casting at room temperature of $20^{\circ} \mathrm{C}$. After demoulding, the specimens were transferred into the water for further curing until the age of the test. All specimens were tested at saturated surface dry condition and carried out according to BS 1881: Part 114. The compressive strength of each sample age was tested immediately after determining the density of the test specimens according to BS 1881: Part 116 for each test age. The static modulus of elasticity test was achieved using $150 \times 300 \mathrm{~mm}$ concrete cylinders according to ASTM C469. The flexural strength and the toughness indices of the specimens were conducted using $100 \times 100 \times 500 \mathrm{~mm}$ samples conforming to BS 1881: Part 118, and ASTM C1018, respectively.

\section{Results and Discussion}

\subsection{EFFECT OF FIBERS ON FLOWABILITY}

The effect of fibers on slump flow of the eight mixes is depicted in Table 4 \& Figure 1 . From the figure, it can be noticed that the inclusion of steel fibers in flowing concrete reduces the flowability and thus higher dosage of SP is needed to achieve the required workability. On the other hand, in concrete mixes with hybrid fibers, higher amount of palm fibers gives higher flowability. In another word, the effect of palm fibers on flowability or workability is much less than that of steel fibers.

\subsection{COMPREsSive STRENGTH}

Table 5 shows the results of compressive strength for all the mixes of high strength flowing concrete (HSFC). The comparison between the reference mix (CF0) with the hybrid fibers mix (CF2 \& CF3) indicates that the use of low volume fraction of palm fibers $0.25 \& 0.5 \%$ as a partial replacement of steel fibers slightly increase the compressive strength of HSFC. This is probably due to the fact that hybrid fibers with different sizes and types would offer different restraint condition [11-13]. On the other hand, the results of mixes (CF4-CF7) show that the increase in percentage of palm fibers in the mix, leads to clear reduction in compressive strength. The reason could be due to low stiffness of this fibers and the displacement of the mortar matrix during the mixing process which would reduce the overall compressive strength of concrete [14]. 


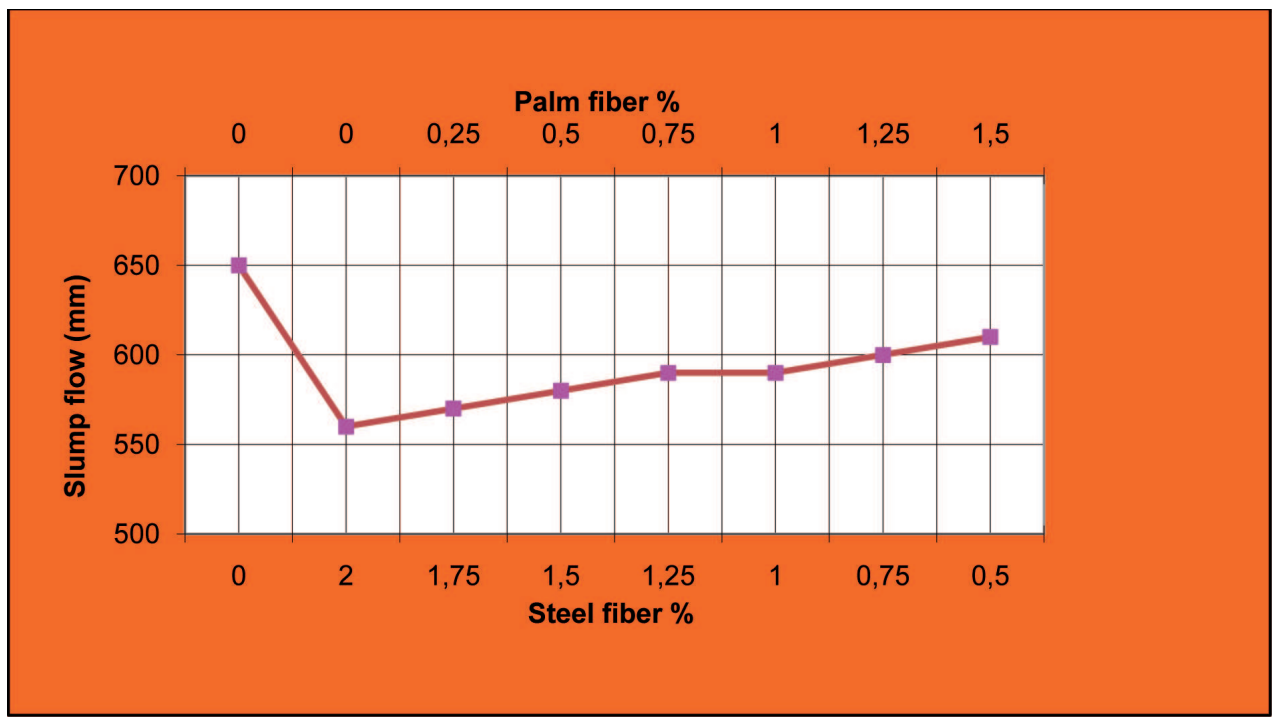

Fig. 1. Relationship between hybrid fibers in concrete mixes with slump flow for all HSFC mixes. Rys. 1.

Table 5

Physical \& Mechanical Properties of Concrete Mixes:

\begin{tabular}{|c|c|c|c|}
\hline Index & $\begin{array}{c}\text { Compressive } \\
\text { strength (MPa) } \\
\text { (28days) }\end{array}$ & $\begin{array}{c}\text { Compressive } \\
\text { strength (MPa) } \\
\text { (90 days) }\end{array}$ & $\begin{array}{c}\text { Static modulus } \\
\text { of elasticity (MPa) } \\
\text { (28 days) }\end{array}$ \\
\hline CF0 & 63.6 & 72.6 & 47.1 \\
\hline CF1 & 66.1 & 75.2 & 53.0 \\
\hline CF2 & 67.3 & 77.1 & 58.3 \\
\hline CF3 & 64.4 & 73.6 & 54.3 \\
\hline CF4 & 55.8 & 66.7 & 51.1 \\
\hline CF5 & 50.4 & 59.6 & 49.6 \\
\hline CF6 & 44.4 & 52.1 & 49.1 \\
\hline CF7 & 39.9 & 48.6 & 48.4 \\
\hline
\end{tabular}

4.3. Modulus of Elasticity (Ec)

The modulus of elasticity results for all HSFC mixes are presented in Table 5. The comparison between (CF0) with (CF1) indicates that the use of $2 \%$ steel fibers leads to an increase in static modulus of elasticity. This is attributed to high stiffness of steel fibers which leads to higher modulus of elasticity for HSFC. On the other hand, the mixes containing hybrid fibers where the palm fibers up to $0.75 \%$ and more (mixes CF4-CF7), the decrease in static modulus of elasticity for HSFC can be noticed. This is can be interpreted using the law of mixtures approach as follow: 
$\mathrm{E}=\mathrm{E}_{1} \mathrm{~V}_{1}+\mathrm{E}_{2} \mathrm{~V}_{2}+-\mathrm{E}_{i} \mathrm{~V}_{i}$

Where $\mathrm{E}$ is the modulus of elasticity for concrete mix, whereas $\mathrm{E}_{i}$ and $\mathrm{V}_{i}$ refer to the modulus of elasticity and volume fraction of mix ingredients respectively [15-17].

The mixes CF2\& CF3 give the highest value of static modulus of elasticity. In these mixes, the palm fibers were included in low volume fraction up to $0.5 \%$ to combine with steel fibers in composite system. The increase of modulus of elasticity in this case, can be attributed due to reduced particle-matrix debonding. On other word, the difference between the modulus of elasticity of the aggregate and the hardened paste becomes small enough which leads to higher bond strength behavior and thus higher modulus of elasticity [17].

\subsection{Flexural Strength}

The flexural strength of the flowing concrete mixes is shown in Table 6. The result of concrete mix containing the single steel fibers of $2.0 \%$ for the mix (CF1) increases the flexural strength of $30 \%$ higher than the control mix (CF0) and this could be due to improved in toughness matrix, compactness and homogeneity of fibers distribution in HSFC [13]. The use of hybrid fibers is also given the limelight in Table 6. The Concrete mix (CF2) (1.75\% steel fibers $+0.25 \%$ palm fibers) was found to give the highest increment up to $38.6 \%$ than the reference mix (CF0). However, the use of palm fibers with volumetric fraction $1 \%$ or more in hybrid combination system (CF5-CF7) eliminates the enhancement of flexural strength. This behavior can be attributed to increments in palm fibers percentages which lead to reduction in flexural strength and compressive strength in descending rate. [18-21]

Table 6

Flexural \& Toughness indices for concrete Mixes:

\begin{tabular}{|l|c|c|c|c|c|c|}
\hline Index & $\begin{array}{c}\text { Flexural } \\
\text { strength (MPa) } \\
\text { (28days) }\end{array}$ & $\begin{array}{c}\text { Flexural } \\
\text { strength (MPa) } \\
\text { (90 days) }\end{array}$ & $\begin{array}{c}\text { Toughness } \\
\text { Index (I 5) } \\
\text { (28 days) }\end{array}$ & $\begin{array}{c}\text { Toughness } \\
\text { Index (I 10) } \\
\text { (28 days) }\end{array}$ & $\begin{array}{c}\text { Toughness } \\
\text { Index (I 5) } \\
\text { (90 days) }\end{array}$ & $\begin{array}{c}\text { Toughness } \\
\text { Index (I 10) } \\
\text { (90 days) }\end{array}$ \\
\hline CF0 & 7.65 & 8.30 & 1 & 1 & 1 & 1 \\
\hline CF1 & 10.35 & 10.75 & 5.05 & 8.12 & 5.97 & 8.57 \\
\hline CF2 & 10.90 & 11.50 & 5.55 & 8.64 & 6.82 & 9.10 \\
\hline CF3 & 10.25 & 11.0 & 6.25 & 8.38 & 6.95 & 9.80 \\
\hline CF4 & 9.55 & 10.15 & 5.08 & 7.35 & 5.85 & 8.70 \\
\hline CF5 & 7.60 & 8.25 & 5.23 & 7.65 & 6.03 & 8.75 \\
\hline CF6 & 7.30 & 8.05 & 4.95 & 6.45 & 5.97 & 8.45 \\
\hline CF7 & 7.20 & 8.0 & 4.67 & 6.18 & 5.76 & 6.72 \\
\hline
\end{tabular}

The performance of the mechanical properties which utilize the different percentages of hybrid fibers is summarized in Figure 2. 


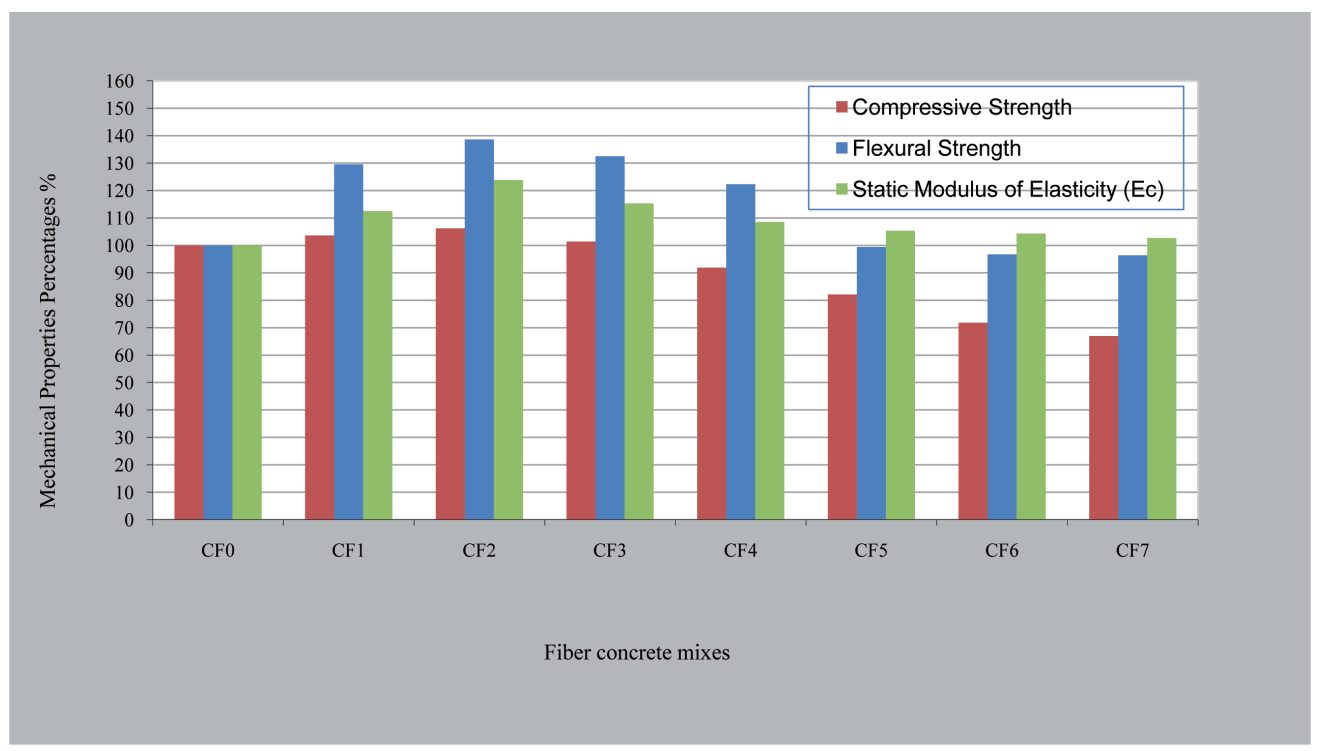

Fig. 2. Relationship between fibers concrete mixes with mechanical properties percentage at 90 days. Rys. 2.

\subsection{ToughnESS InDices}

Toughness is also defined as the energy absorption capacity. The toughness indices can be determined according to ASTM C1018. The indices I-5 and I-10 can be calculated from this test where the ratio of the area under the load deflection curves up to 3 and 5.5 times the first crack deflection, divided by the area up to the first crack deflection respectively. Table 6 illustrates the results of the I-5 \& I-10 for $28 \& 90$ days. The toughness indices are found to increase with the increasing fibers content, and the behavior indicates the ability of fibers in arresting cracks at both micro-and macro-levels. At micro-level, fibers inhibit the initiation of cracks, while at macro-cracks; fibers provide effective bridging and impart sources of toughness and ductility. [22,23]. This was also supported by other researchers[24], where the flexural toughness can be increased as the fibers volume fraction is increased and similarly higher values of the toughness indices can be achieved at higher fibers volume fractions. The Figures 3 show the effects of using different volume fractions of hybrid fibers on the toughness indices at 90 days of normal water curing respectively. The use of hybrid fibers (CF3) (1.5\% steel fibers $+0.5 \%$ palm fibers) was found to show the highest improvement for the toughness indices. Figure 4 shows the load-deflection curve for all the mixes. This curve illustrates more about the conductivity of the hybrid combination of steel fibers and palm fibers These results are similar to some findings reported by others [23-27], where the stronger and stiffer steel fibers enhance the first crack and ultimate strength, whereas the more flexible and ductile fibers (palm fibers in this study) improve the 


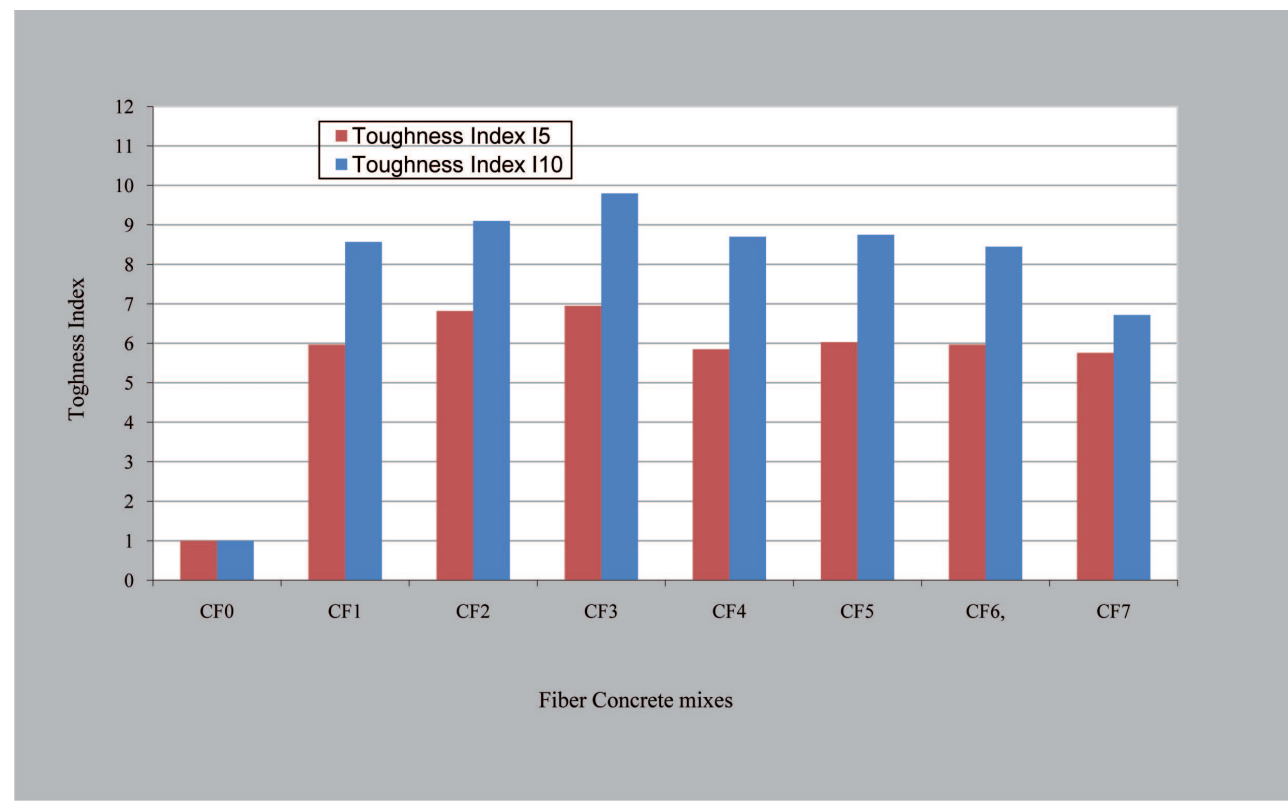

Fig. 3. Relationship between fibers concrete mixes with toughness index at 90 days. Rys. 3.

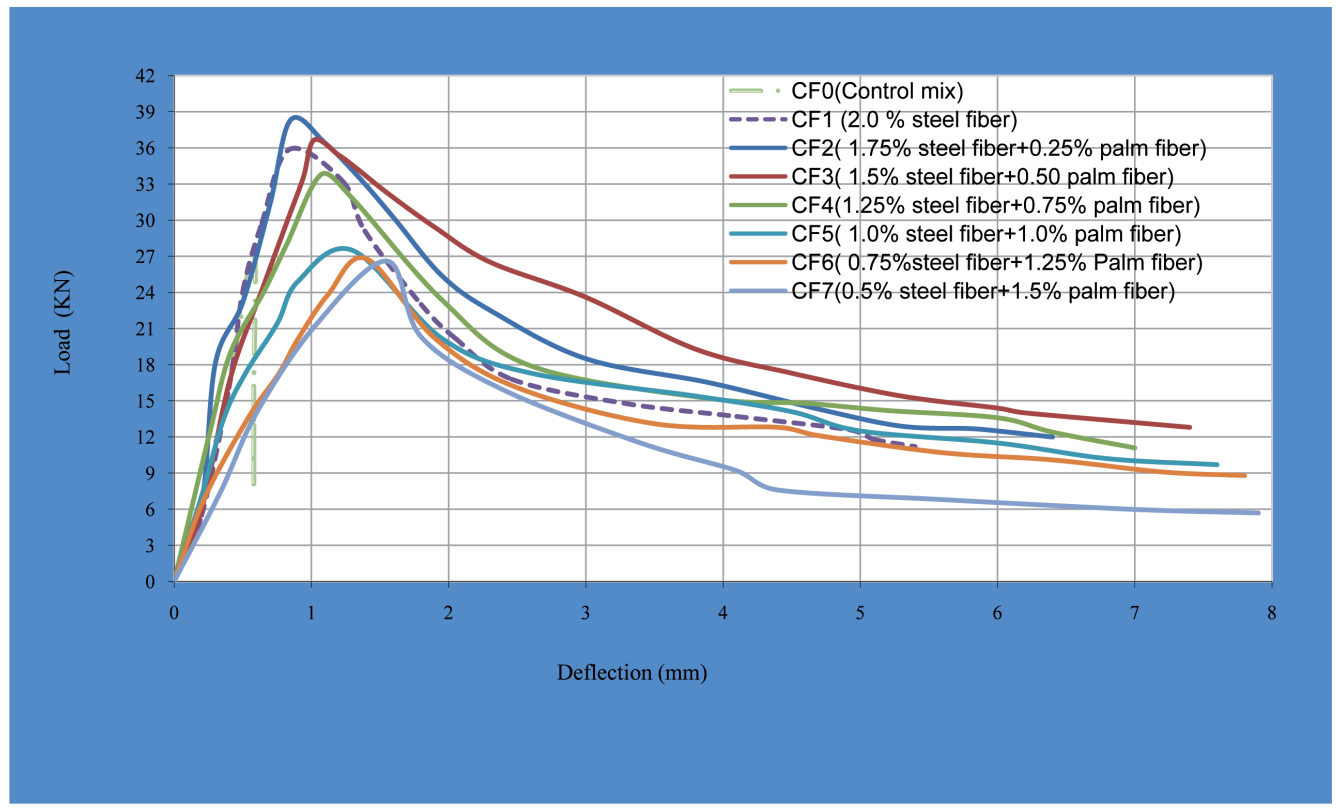

Fig. 4. Load-deflection curves for all HSFC mixes reinforced by hybrid fibers.

Rys. 4. 
toughness and strain capacity in the post crack zone. In addition, the reason could be also due to smaller diameter or higher aspect ratio of palm fibers and this would increase the fibers availability and thus delaying the growth of micro cracks [23, 27]. However, the increase of palm fibers in the concrete mixes decreases the toughness of steel-palm concrete where there are no sufficient steel fibers in the system to bridge the wider cracks [27].

\section{Conclusions}

The results of an experimental study on the high strength flowable concrete reinforced with various volume fractions of steel fibers reveal the following conclusions:

1- The compressive strength results show that the use of more than $0.5 \%$ of palm fibers in hybrid fibers mixes reduces the compressive strength. This is due to the low stiffness and the displacement of the mortar matrix of the mixes leading to reduction in overall compressive strength.

2 - The flexural strength of concrete mixes containing hybrid fibers $(1.75 \%$ steel fibers $+0.25 \%$ palm fibers) gives the higher increment in flexural strength, while the use of palm fibers with volumetric fraction $1 \%$ or more in hybrid combination system eliminates the enhancement of flexural strength.

3 - The results show that the use of hybrid fibers $(1.5 \%$ steel fibers $+0.5 \%$ palm fibers) in specimens has increased the toughness indices in the matrix significantly compared with mix of $2 \%$ when the single steel fibers was used. Thus indicates that the use of hybrid fibers combinations in reinforced concrete would enhance their flexural toughness \& rigidity and enhance their overall performances.

4- The results indicated that the uses of low fractions of palm fibers with the $1.5 \%$ or $1.75 \%$ of steel fibers enhance the mechanical properties of concrete and thus may result in a higher performance in term of durability of concrete as well.

\section{AcKNOWLEDGEMENT}

The work described in this paper was a part of $\mathrm{PhD}$ research program of the first author which is supported by a research grant from the Universiti Sains Malaysia.

\section{REFERENCES}

1. F. Burak, S. Turkel \& Y. Altuntas, Hybird fibers reinforced self-compacting concrete with high-volume coarse fly ash, Const. \& Build. Mater. 21, 150-156, 2007.

2. F. Burak, S. Turkel \& Y. Altuntas, Effects of steel fibers reinforcement on surface wear resistance on self compacting repair mortar, Cem. \& Conc. Comp. 29, 391-396, 2007.

3. L. GANG, K. WANG \& T.J. RudolphI, Modeling reheological behavior of highly flowable mortar using concepts of particle and fluid mechanics, Cem. \& Conc. Comp. 30, 1-12, 2008. 
4. H. Окамura \& M. Ouchi, Self compacting concrete, J. Adv.Concr Technol, 1(1), 1-15, 2003.

5. K.H. Кнауат, R. Morin, Performance of self-consolidating concrete used to Repair parapet wall in Montreal, Proceedings of the first north American conference on the design and use of self-consolidating concrete, 475-481, 2002.

6. M. Sahmaran, A. Yurtseven \& O.I. Yaman, Workability of hybrid fibers reinforced self-compacting concrete. Building \& Environment Journal, 40, 1672-77, 2005.

7. W. Sun, H. CHEN, X. Luo \& H. QIAN, The effect of hybrid fibers and expansive agent on the shrinkage and permeability of high-performance concrete, Cem. \& Conc. Research, 31, 595-01, 2001.

8. A. Bentur \& S. Mindess, Fibers Reinforced Cementitious Composites, $2^{\text {nd }}$ ed. 2007, Taylor \& Francis.

9. W. YAO, J. LIE \& K. WU, Mechanical properties of hybrid fibers- reinforced concrete at low volume fibers fraction, Cem. \& Conc.e Research; 33, 27-30, 2003.

10. The American Concrete Institute (ACI 211.1-91) Standard P "Standard Practice for selecting Proportions for Normal,Heavyweight, and Mass Concrete", ACI Manual of Concrete Practice 2000, Part 1: Materials and General Properties of Concrete.

11. S. Mustafa \& O.I. Yaman, Hybrid fibers reinforced self compacting concrete with a high volume coarse fly ash, Construction \& Building Materials 21, 150-156, 2007.

12. G. StefFen \& C.W. Joost, Parameter study on the influence of steel fibers and coarse aggregate content on the fresh properties of self compacting concrete, Cement \& Concrete Research 31, 1793-1798, 2001.

13. B. Chen \& J. Liu, Residual strength of hybrid-fibers-reinforced high-strength concrete after exposure to high temperatures, Cement \& Concrete Research 34, 1065-69, 2004.

14. I. Markovic, J.C. Walraven \& M.J. VAN, Self compacting hybrid fibers concrete-mix design, workability and mechanical properties, Proceedings of third international symposium on self-compacting concrete, 763-775, 2003.

15. P.K. Mehta \& P.J.M. Monterio, Concrete, structures, properties and materials, $2^{\text {nd }}$ ed. New Jersey, USA: Prentice-Hall: pp. 447, 1993.

16. A. Mor, Steel-concrete bond in high strength-lightweight concrete, ACI Materials Journal 89(1), 76-82, 1992.

17. O. Kayali, M.N. Haque \& B. Zhu, Some characteristics of high strength fibers reinforced lightweight aggregate concrete, Cement \& Concrete Composites, 25, 207-13, 2003.

18. D.J. Hannant, Fibers cement and fibers concrete, Chichester 1987, UK :Wiley.

19. A.M. Neville, Properties of concrete, 1995, Fourth and Final edition.

20. A.C. Aydin, Self compactability of high volume hybrid fibers reinforced concrete, Const. \& Build. Material 21, 1149-54, 2007.

21. S.K. Al-Oraimi \& A.C. Seibi, Mechanical characterization and impact behavior of concrete reinforced with natural fibers, Composite structure, 32, 165-171, 1995.

22. P.N. Balaguru \& S.P. Shah, Fibers Reinforced Cement Composites, McGraw-Hill Inc., 1992, New York.

23. N. Banthia \& M. SAPPakitTiPAKoRn, Toughness enhancement in steel fibers reinforced concrete through fibers hybridization, Cem. \& Conc. Research 37, 1366-72, 2007.

24. M.C. Nataraja, N. Dhang \& A.P. Gupta, Stress-strain curves for steel fibers reinforced concrete under compression, Cem. \& Conc. Comp. 21, 383-390, 1999.

25. R.F. Toledo, K. Ghavami, G.L. England \& K. Scrivener, Development of vegetable fibre-mortar composites of improved durability, Cem. \& Conc. Research, 25, 185-96, 2003.

26. D. Feldman \& Z. Zheng, Synthetic fibers for fibers concrete composites [in:] Ronald K. Eby, et al., (Eds.), High Performance Polymers and Polymer Matrix Composites: Symposium Held April 13-16, 1993, San Francisco California, U.S.A., Material Research Society Symposia Proceedings vol. 305, Materials Research Society, Pittsburgh, 123-128, 1993. 
27. A. Sivakumar \& M. Santhanam, Mechanical properties of high strength concrete reinforced with metallic and non-metallic fibers, Cem. \& Conc. Comp., 29, 603-08, 2007.

28. American Society Tests of Material, ASTM C 143, C469 \& C1018 Annual book of ASTM Standard, Volume 04.02"ASTM international. www.astm.org.

29. BSI British Standard" methods for determination of density of hardened concrete", 1983, BS 1881: Part 114, British Standard.

30. BSI British Standard" methods for determination of compressive strength of concrete cubes" 1983 , BS 1881: Part 116, British Standard.

31. BSI British Standard" methods for determination of flexural strength" 1983, BS 1881: Part 118, British Standard.

Remarks on the paper should be sent to the Editorial Office

no later than December 30, 2011
Received January 10, 2011 revised version May 30, 2011 